\title{
Thermotropic Main Chain Polyesters with Polymethylene Spacers and Their Low Molecular Weight Model Compounds-Odd-Even Effect of Polymethylene Spacers
}

\author{
Jung-Il JIN, E-Joon CHOI, Seog-Cheol RYU, \\ and Robert W. LENZ* \\ Chemistry Department, College of Sciences, Korea University, \\ 1-Anam Dong, Seoul 132, Korea \\ * Chemical Engineering Department, University of Massachusetts, \\ Amherst, MA 01002, U.S.A.
}

(Received March 18, 1985)

\begin{abstract}
A series of main-chain thermotropic polyesters which have an alternating sequence of mesogenic units and polymethylene spacers as well as their model compounds with two terminal mesogenic units and central spacers were prepared. Their liquid crystalline behavior, especially their thermal transition properties and nature of mesophases were compared with each other. The polymers and the low molecular weight model compounds exhibited in their transition temperatures distinctive odd-even dependence on the number of methylene units in the spacer. All of them formed nematic mesophases in melts. The liquid crystalline properties of the polymers and the model compounds were studied by differential scanning calorimetry and on the hot-stage of a polarizing microscope.
\end{abstract}

KEY WORDS Thermotropic Polyesters / Polymethylene Spacers / Model Compounds / Transition Temperatures / Odd-Even Effect / Nematic Phase /

In recent years mesomorphic properties of many different types of thermotropic polymers have been reported. ${ }^{1-5}$ Among the many interesting observations made for the polymers, the odd-even dependence of transition temperatures of main chain thermotropic polymers with polymethylene spacers is a matter of importance, which generalizes the thermal behavior of a series of polymers with varying lengths of spacers. ${ }^{3,5}$ However, direct comparison of thermal transition temperatures obtained experimentally for a series of polymers may become erroneous due to strong dependence of transition temperatures not only on molecular weights of the polymers but also on their polydispersity. Even though, one could utilize various fractionation methods to prepare samples of a homologous series of polymers to have comparable molecular weights and molecular weight distributions, as is very well known, it is extremely time consuming. Moreover, many of the polymers, especially those with high transition temperatures may undergo thermal degradations before their transitions, which would cause difficulties in thermal analysis. While trying to establish the structure-property relationship of the thermotropic main chain polyesters having flexible spacers, we became interested in the liquid crystalline behavior of low molecular weight model compounds to see whether there exists any correlation between their properties and those of the corresponding polymers, especially in thermal behavior and in the nature of mesophases derived from them. It is obvious that experi- 
mental problems caused by the difference in MW's and MWD's of a homologous series of polymers are absent when low molecular weight compounds are studied.

In the present article, we would like to report the thermal behavior of Series I polymers and of Series II model compounds shown below. The nature of mesophases formed by the polymers were also compared with those formed by the model compounds. Thermal behavior of the polymers and their corresponding low molecular weight compounds were examined by DSC method. Optical textures were observed on the hotstage of a polarizing microscope.

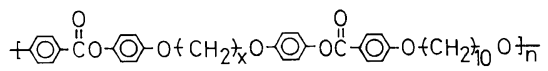

$$
\begin{aligned}
& x=2-10
\end{aligned}
$$

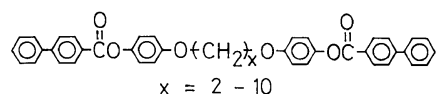

\section{EXPERIMENTAL}

\section{Synthetic Method of Polymers I}

The synthetic methods of the Polymers I with $x=6,8$, and 10 were reported earlier by Griffin and Havens. ${ }^{4}$ All of the polymers were prepared by the interfacial polycondensation method following the method used by Griffin and Havens:

$$
\begin{aligned}
& \mathrm{Cl}-\mathrm{C}-\left(\mathrm{O}-\mathrm{O}+\mathrm{CH}_{2} \frac{1}{10} \mathrm{O}-(\mathrm{O})-\mathrm{C}-\mathrm{Cl}+\mathrm{HO}-\left(\mathrm{O}-\mathrm{O}+\mathrm{CH}_{2}+\mathrm{O} \times-(\mathrm{O})-\mathrm{OH}\right.\right. \\
& \longrightarrow \text { Polymers I }
\end{aligned}
$$

\section{Synthetic Method of Compounds II}

The Compounds II were synthesized via the following route:

$$
\begin{aligned}
& \mathrm{Br}+\mathrm{CH}_{2} \mathrm{H}_{x} \mathrm{Br}+\mathrm{HO}-\mathrm{O}-\mathrm{OH} \frac{\mathrm{KOH}}{\mathrm{C}_{2} \mathrm{H}_{5} \mathrm{OH}}
\end{aligned}
$$

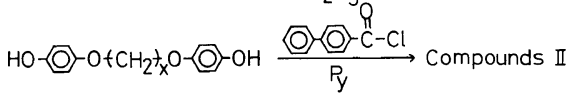

Since the dihydroxy compounds, $\alpha, \omega$-bis $(p$ hydroxyphenoxy)alkanes, used for the last reaction are known ones, ${ }^{4}$ only the final step of a representative synthetic method is described: $p$-phenylbenzoyl chloride $\left(3.5 \times 10^{-3} \mathrm{~mol}\right)$ dissolved in $10 \mathrm{ml}$ dry pyridine was added at room temperature slowly to a $10 \mathrm{ml}$ pyridine solution of an $\alpha, \omega$-bis( $p$-hydroxyphenoxy) alkane $\left(1.5 \times 10^{-3} \mathrm{~mol}\right)$. The reaction mixture was stirred under a nitrogen atmosphere for 2 hours at room temperature and then for 1 more hour at $60^{\circ} \mathrm{C}$. At the end of the reaction the mixture was poured into cold distilled water with vigorous stirring. The precipitates were washed with dilute aquous $\mathrm{NaOH}$ solution and then again with distilled water. The crude products were recrystallized from toluene/1-butanol mixture (vol ratio= $30: 70$ ). The compounds were confirmed by elemental analysis (Table II) and their IR and NMR spectra.

\section{Characterization and Identification of Polymers} $I$ and Compounds II

The structures of the polymers and the compounds were confirmed by IR spectra obtained on a Perkin-Elmer 710 B IR spectrophotometer. The structures of the model compounds were further confirmed by elemental analysis and also by their proton NMR spectra obtained on Varian Associate EM 360A $(60 \mathrm{MHz})$ NMR instrument. The elemental analysis of the Compounds II were performed by the Microelemental Analysis Laboratory of the University of Massachusetts.

The solution viscosity of the polymers was measured at $30 \pm 0.1^{\circ} \mathrm{C}$ using a Ubbelohde type viscometer. The polymers having odd numbers of methylene units in the spacer were found to be soluble at room temperature in 1,1,2,2-tetrachloroethane (TCE). The number average molecular weights of these polymers were determined osmometrically using Knauer vapor pressure osmometer (Model nr. 11.00) at $55^{\circ} \mathrm{C}$.

Thermal behavior of the samples were studied on a du Pont 910 Thermal Analyzer under a nitrogen atmosphere. Heating and cooling 
rates were maintained at $10 \mathrm{~K} \mathrm{~min}^{-1}$ in the compounds and $20 \mathrm{~K} \mathrm{~min}^{-1}$ in the polymers, respectively. Indium was employed for calibration. Thermodynamic parameters $(\Delta H$ 's and $\Delta S$ 's) were calculated based on the endothermic peak areas in the DSC curve and on the weight of the sample using indium $\left(\Delta H_{\mathrm{m}}=6.8 \mathrm{cal} \mathrm{g}^{-1}\right)$ as a standard. The DSC curves obtained on second heating cycles were used to obtain all of the experimental data. The positions of peak maxima were taken as transition temperatures. The nature of the mesophases was examined on a hotstage (Mettler FP-5) attached to a polarizing microscope (Leitz, Ortholux).

\section{RESULTS AND DISCUSSION}

\section{General Properties of Polymers I and Compounds II}

The polymers with even number of methylene units in the spacer were soluble in the mixture of phenol and TCE ( $60: 40$ by weight), while those with odd number of methylene units were soluble in TCE. The polymer yields, inherent viscosity of polymer solutions, and the number average molecular weights of the polymers with odd-numbered polymethylene spacer are shown in Table I. It should be noted from the table that the molecular weights of polymers are rather low and vary greatly from one another ranging from about 2000 to 11000. Optimization of polymerization condition to obtain higher molecular weight polymers was not attempted. The product yields and the results of elemental analysis of Compounds II are tabulated in Table II. The yields are, in general, high and the elemental analysis results are in good agreement with calculated values. The structures of the compounds were further confirmed by their IR and proton NMR spectra.

\section{Thermal Behavior of Polymers I and Com- pounds II}

All of the polymers and the model com-
Table I. Properties of Polymers I

\begin{tabular}{rccc}
\hline$x$ & Yield/wt $\%$ & $\eta_{\text {inh }}{ }^{\mathrm{a}}$ & $M_{n}{ }^{\mathrm{b}}$ \\
\hline 2 & 83.8 & 0.79 & - \\
3 & 87.0 & 0.31 & 3400 \\
4 & 92.3 & 0.53 & - \\
5 & 82.7 & 0.61 & 10600 \\
6 & 88.2 & 0.53 & - \\
7 & 80.1 & 0.33 & 3000 \\
8 & 89.3 & 0.42 & - \\
9 & 86.1 & 0.29 & 1900 \\
10 & 79.2 & 0.30 & - \\
\hline
\end{tabular}

a Inherent viscosity $\left(\eta_{\text {inh }}\right)$ was measured on $0.5 \mathrm{~g} \mathrm{dl}^{-1}$ solution in a mixture of TCE and phenol $(\mathrm{w} / \mathrm{w}=40: 60)$ at $30 \pm 0.1^{\circ} \mathrm{C}$.

b The number average molecular weights determined at $55^{\circ} \mathrm{C}$ by vapor pressure osmometry.

Table II. The yields and the results of elemental analysis of Compounds II

\begin{tabular}{|c|c|c|c|}
\hline \multirow{2}{*}{$x$} & \multirow{2}{*}{ Yield $/ w t \% a$} & \multicolumn{2}{|c|}{ Elemental analysis $/ \mathrm{wt}^{\circ} \mathbf{o}^{\mathrm{b}}$} \\
\hline & & $\mathrm{C}$ & $\mathrm{H}$ \\
\hline 2 & 95.4 & $79.11(79.18)$ & 4.88 (4.99) \\
\hline 3 & 95.4 & $78.95(79.33)$ & $5.15(5.21)$ \\
\hline 4 & 96.3 & $79.40(79.47)$ & $5.47(5.41)$ \\
\hline 5 & 85.2 & $79.63(79.60)$ & $5.62(5.60)$ \\
\hline 6 & 89.0 & $79.18(79.73)$ & $5.75(5.79)$ \\
\hline 7 & 95.5 & $79.87(79.85)$ & $5.89(5.97)$ \\
\hline 8 & 93.6 & $79.91(79.96)$ & $6.18(6.14)$ \\
\hline 9 & 94.5 & $80.02(80.08)$ & $6.39(6.30)$ \\
\hline 10 & 92.6 & $80.11(80.18)$ & $6.50(6.46)$ \\
\hline
\end{tabular}

a The product yields listed are those for the final step of preparation.

b The values in parentheses are theoretical ones.

pounds revealed two distinctive endothermic peaks on the DSC curves of heating runs. The first peaks corresponded to the melting transition from solid into a mesophase and the second to the phase transition from the mesophase to an isotropic melt. Such transitions were reversible as observed on the DSC curves obtained from the heating and cooling cycles of DSC analysis (Figures 1 and 2). This indicates that all of the polymers and compounds were enantiotropic. According to Figure 2 a small peak appeared around $130^{\circ} \mathrm{C}$ 


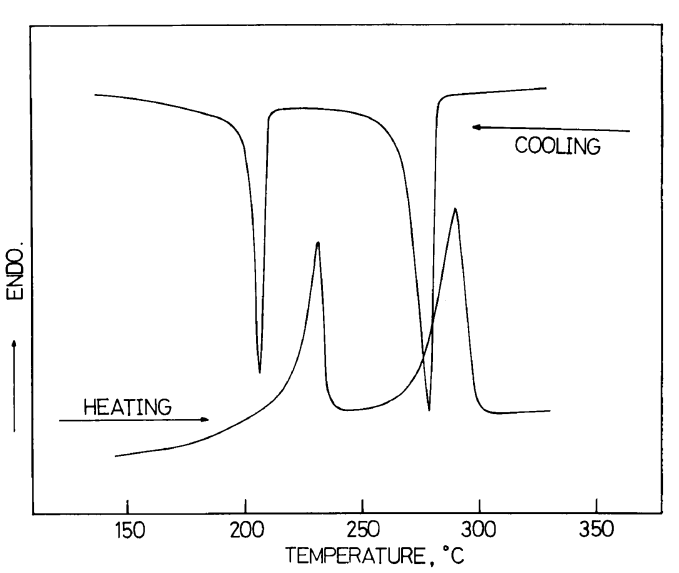

Figure 1. DSC curves of Polymer I with dimethylene spacer. Heating and cooling rates were $20 \mathrm{Kmin}^{-1}$.

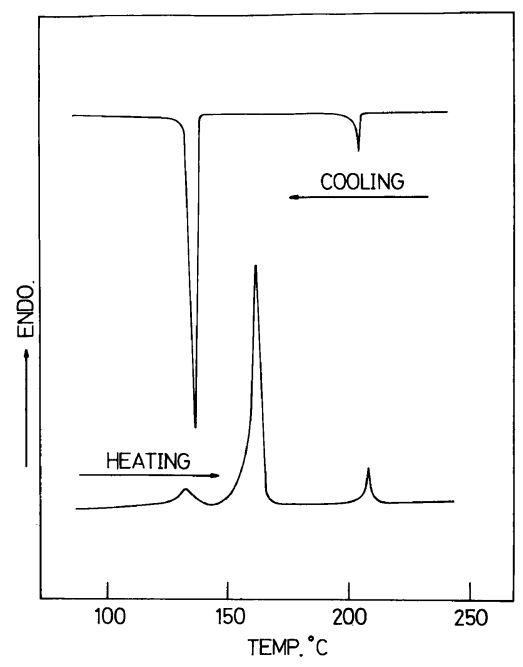

Figure 2. DSC curves of Compound II with heptamethylene spacer. Heating and cooling rates were $10 \mathrm{~K} \mathrm{~min}^{-1}$.

in addition to the melting and isotropization peaks. This peak reproducibly reappeared on the 2 nd and even on further cycles of DSC analysis. It is possible that this compound is polymorphic and the first peak corresponds to crystal $\rightarrow$ crystal transition. Similar multiple transitions were reported for other model compounds and liquid crystalline polyesters. ${ }^{1,4,6}$ All of the present model compounds and a part of the polymers exhibited resemblant
Table III. Thermal properties of Polymers $\mathrm{I}^{\mathrm{a}}$

\begin{tabular}{rllrrrr}
\hline$x$ & $T_{\mathrm{m}} /{ }^{\circ} \mathrm{C}$ & $T_{\mathrm{i}} /{ }^{\circ} \mathrm{C}$ & $\Delta H_{\mathrm{m}}$ & $\Delta S_{\mathrm{m}}$ & $\Delta H_{\mathrm{i}}$ & $\Delta S_{\mathrm{i}}$ \\
\hline 2 & 223 & 279 & 9.0 & 18.1 & 12.5 & 22.6 \\
3 & 164.5 & 185 & 6.2 & 12.6 & 7.2 & 14.8 \\
4 & 217 & 244 & 8.0 & 18.0 & 11.5 & 22.3 \\
5 & 170.5 & 206.5 & 5.2 & 11.7 & 8.4 & 17.6 \\
6 & 214 & 239.5 & 9.7 & 20.0 & 13.7 & 26.7 \\
7 & 150 & 193 & 11.7 & 27.6 & 9.6 & 20.6 \\
8 & 182.5 & 216 & 9.8 & 21.5 & 18.1 & 36.9 \\
9 & 142.5 & 172.5 & 9.1 & 21.9 & 10.2 & 22.9 \\
10 & 159 & 189 & 8.8 & 20.3 & 14.1 & 30.4 \\
\hline
\end{tabular}

a All of the values of $\Delta H$ 's are in $\mathrm{kJ} \mathrm{mol}^{-1}$ and those of $\Delta S$ 's in $\mathrm{J} \mathrm{mol}^{-1} \mathrm{~K}^{-1}$.

Table IV. Thermal properties of Compounds $\mathrm{II}^{\mathrm{a}}$

\begin{tabular}{rlllllrl}
\hline $\mathrm{x}$ & $T_{\mathrm{m}} /{ }^{\circ} \mathrm{C}$ & $T_{\mathrm{i}} /{ }^{\circ} \mathrm{C}$ & $\Delta H_{\mathrm{m}}$ & $\Delta S_{\mathrm{m}}$ & $\Delta H_{\mathrm{i}}$ & $\Delta S_{\mathrm{i}}$ & $\Delta S_{\mathrm{i}} / \Delta S_{\mathrm{t}}{ }^{\mathrm{b}}$ \\
\hline 2 & 234.5 & 296 & 39.5 & 77.8 & 7.6 & 13.4 & 0.15 \\
3 & 187 & 205 & 32.7 & 71.1 & 2.2 & 4.6 & 0.07 \\
4 & 197.5 & 241.5 & 17.0 & 36.0 & 6.5 & 12.6 & 0.26 \\
5 & 190.5 & 202 & 20.9 & 45.0 & 2.3 & 5.0 & 0.10 \\
6 & 196 & 233.5 & 33.0 & 70.4 & 6.1 & 12.0 & 0.15 \\
7 & 161 & 204.5 & 27.4 & 63.1 & 4.0 & 8.4 & 0.12 \\
8 & 188 & 207.5 & 28.6 & 61.9 & 6.4 & 13.4 & 0.18 \\
9 & 156 & 195 & 20.2 & 47.1 & 4.5 & 9.6 & 0.17 \\
10 & 186.5 & 194.5 & 33.4 & 72.6 & 6.6 & 14.0 & 0.16 \\
\hline
\end{tabular}

a All of the values of $\Delta H$ 's are in $\mathrm{kJ} \mathrm{mol}^{-1}$ and those of $\Delta S^{\prime}$ 's in $\mathrm{J} \mathrm{mol}^{-1} \mathrm{~K}^{-1}$

b $\Delta S_{\mathrm{t}}$ stands for total entropy change for melting and isotropic transitions, i.e., $\Delta S_{\mathrm{m}}+\Delta S_{\mathrm{i}}$.

multiple melting transitions. The values of melting $\left(T_{\mathrm{m}}\right)$ and isotropization $\left(T_{\mathrm{i}}\right)$ temperatures obtained from the heating DSC runs of the polymers and compounds are tabulated in Tables III and IV. These data and those for the compounds of Series III, whose thermal and liquid crystalline behavior were reported recently by $\mathrm{us}^{7}$ are presented in Figures 3 and 4 for comparison. As one can see from the figures,

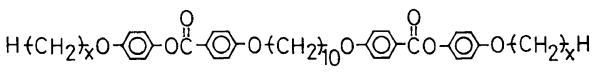

the transition temperatures, $T_{\mathrm{m}}$ and $T_{\mathrm{i}}$, of Polymers I and Compounds II decreased in a zig-zag fashion with $x$ and showed the so- 
called odd-even effect. These temperatures for polymers and compounds with even numbers of methylene units in the spacer were consistently higher than those of odd numbers. The existence of an odd-even effect also suggests that the conformation around $\mathrm{C}-\mathrm{C}$ bonds of the spacer is influenced by the presence of rigid rod-like segment attached to its both ends. $^{8,9}$ There is some experiemental evidence that the polymethylene spacer is mainly in a trans conformation. ${ }^{10 a, b}$ If this is indeed the case, the even numbered polymethylene spacers would tend to have a more or less colinear or parallel alignment of mesogenic unit, while the odd numbers would result in angled orientation of mesogenic units. ${ }^{8,9}$ This is in line with the higher transition temperatures for even numbers than those of odd ones. Such an odd-even effect has been repeatedly observed for other polymers and low molecular weight compounds. ${ }^{5,11-13,14}$ Abe et al. ${ }^{15}$ recently conducted a deuterium NMR studies on the orientational order in dimeric model compounds and found that the compound with a central polymethylene spacer of even number of methylene unit had significantly higher order parameter than that with odd number of methylene unit. They concluded that, for the even member, the colinear alignment of the two terminal mesogenic groups is one of the preferred conformation while the similar colinear alignment requires high-energy conformations for the odd member.

However, the transition temperature of the compounds of Series III did not show the same trend in $T_{\mathrm{m}}$ as well as $T_{\mathrm{i}}$. It is known that unstrained terminal alkyl groups possess a higher degree of conformational freedom resulting in irregular stereochemistry around C$\mathrm{C}$ bonds. This in turn would give rise to an irregular dependence of transition temperatures on the number of methylene units in the alkyl groups. Comparing the thermal behavior of Compounds II and III, one can conclude that the structure of Compounds II simulates

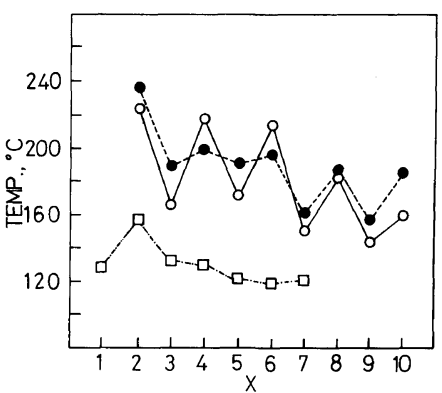

Figure 3. The dependence of melting temperatures $\left(T_{\mathrm{m}}\right)$ of Polymers I (O), Compounds II (O) and Compounds III $(\square)^{7}$ on the length of polymethylene spacer.

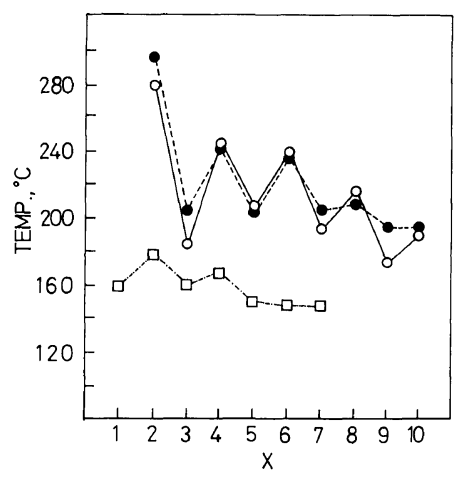

Figure 4. The dependence of isotropic transition temperatures $\left(T_{\mathrm{i}}\right)$ of Polymers I (O), Compounds II (O) and Compounds III $(\square)^{7}$ on the length of the polymethylene spacer.

thermal behavior of Polymers I much better than those of Series III.

The compounds of Series II have terminal phenyl substituents on both mesogenic units. We have prepared a series of compounds with different substituents and found that the phenyl substituent resulted in the thermal transition temperatures close to those Polymers I. This is the reason why the compounds of Series II were taken as model compounds in this investigation. Similar observations were made earlier by us for Polymers $\mathrm{IV}^{4}$ and Compounds $\mathrm{V}^{13}$ shown below:

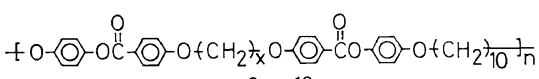

$$
\begin{aligned}
& x=2-10
\end{aligned}
$$

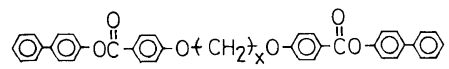

$$
\begin{aligned}
& x=2-10
\end{aligned}
$$




\section{J.-I. JIN et al.}

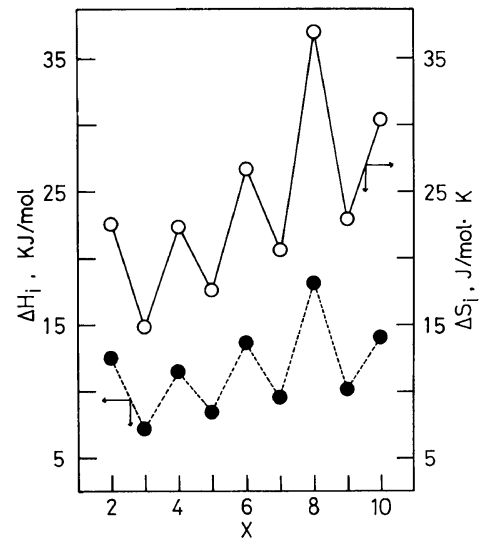

Figure 5. The dependence of the values of $\Delta H_{\mathrm{i}}$ and $\Delta S_{\mathrm{i}}$ of Polymers I on the length of the spacer, $x$.

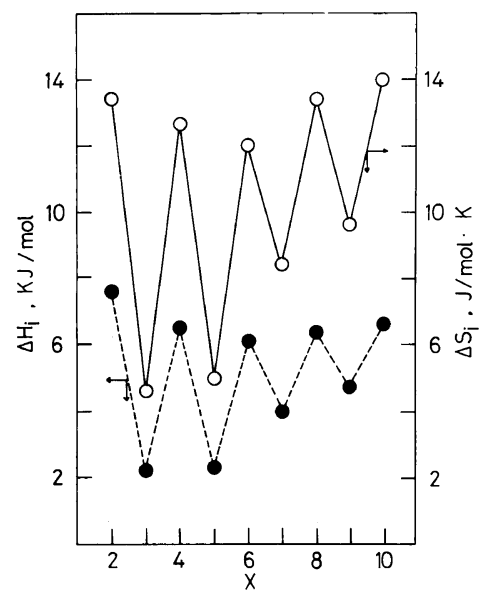

Figure 6. The dependence of the values of $\Delta H_{\mathrm{i}}$ and $\Delta S_{\mathrm{i}}$ of Compounds II on the length of the spacer, $x$.

Figures 5 and 6 show how the values of $\Delta H_{\mathrm{i}}$ and $\Delta S_{\mathrm{i}}$ of the Polymers I and Compounds II respectively change with $x$. The figures reveal a definite odd-even effect on $\Delta H_{\mathrm{i}}$ as well as $\Delta S_{\mathrm{i}}$ for both polymers and model compounds. The slightly lower degree of regularity observed for the polymers may be ascribed to the vast differences in their molecular weights. Roviello and Sirigu $^{5}$ earlier observed clear odd-even effects for the transition temperatures and $\Delta S_{\mathrm{i}}$ for main chain thermotropic polymers consisting of azoxybenzene type mesogenic units and polymethylene spacers. The higher values of
$\Delta S_{\mathrm{i}}$ for even members can be taken as a suggestion of a higher degree of order in their liquid crystal phases than for those of odd ones. Recently $\mathrm{Abe}^{8}$ made a thorough conformational analysis to provide a theoretical explanation for the odd-even effect of liquid crystalline semiflexible polyesters with polymethylene spacers. He also calculated order parameters for the mesophases formed by the odd and even series of the polymers. All of his results are in line with our present observations. The distribution of chain sequence extension of thermotropic polyesters with polymethylene spacers were calculated by Yoon ${ }^{9}$ using isomeric state model. Yoon's results also point to the odd-even effect of the spacers.

Another interesting fact to be noted from Table III and IV is that $\Delta S_{\mathrm{i}}$ values of polymers are consistently higher than those of the model compounds. This may be due to the higher degree of restraint experienced by the mesogenic units in the mesophases formed by the polymers than the model compounds. It was earlier observed by Blumstein et al. ${ }^{11}$ that, even for a same thermotropic polymer, $\Delta S_{\mathrm{i}}$ increased rapidly with the degree of polymerization. Table IV shows also that the values of $\Delta S_{\mathrm{i}}$ ranged from 7 to $26 \%$ of total entropy change, $\Delta S_{\mathrm{t}}$, which are very high when compared with corresponding values of similar compounds having only one mesogenic unit. Such phenomena were repeatedly observed by us and others for various systems ${ }^{11-13,14}$. In addition, it should be pointed out that, contrary to low molecular weight compounds, $\Delta H_{\mathrm{i}}$ values of the polymers are in general greater than the values of $\Delta H_{\mathrm{m}}$ (Table III)..$^{3-5}$ This must be due to low degree of crystallinity of the polymers.

\section{Liquid Crystalline Organization of Polymers I and Compounds II}

Figure 7(a) shows a typical optical texture observed for Polymers I, and Figure 7(b) for Compounds II. All of the optical textures 


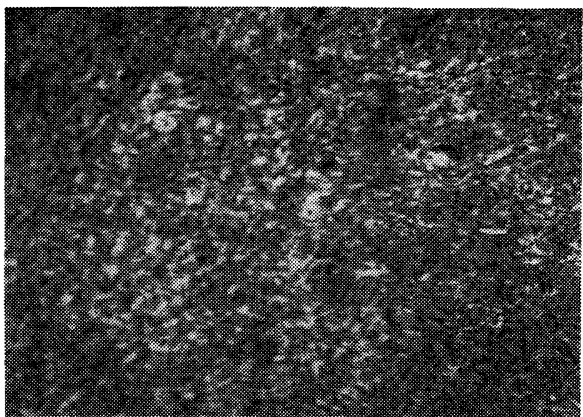

(a)

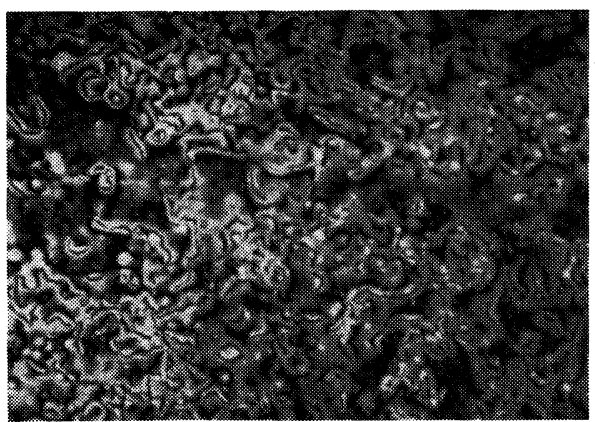

(b)

Figure 7. Microphotography of Polymer I with dimethylene spacer $(x=2)$ taken at $268^{\circ} \mathrm{C}$ (a) and Compound II with trimethylene spacer $(x=3)$ taken at $201.5^{\circ} \mathrm{C}$ (b) (Magnification: $100 \times$ ).

observed through the microscope were those typical to nematics. And the polymers were found to be miscible with low molecular weight nematic compounds in their mesophases. ${ }^{16}$ The results of miscibility study will be published shortly. Therefore, we can conclude that Polymers I and Compounds II formed only nematic phases upon melting. On the contrary, the compounds of Series III formed nematic or smectic phases depending on the length of the terminal alkyl groups. ${ }^{7}$ Here again, we come to the conclusion that the Compounds II are better than Compounds III in duplicating the liquid crystalline behavior of Polymers I. In other words, the compounds of Series II are better models for Polymers I than those of Series III.

\section{CONCLUSION}

From the present investigation the following conclusions can be drawn:

1. All of the polymers and compounds reported in this article were enantiotropic, thermotropic compositions.

2. Polymers I and Compounds II showed an odd-even dependence of transition temperatures on the number of methylene units of the spacers.

3. The Compounds II were found to be better model compounds than those of Series III for Polymers I.

4. All of the Polymers I and Compounds II presented in this articles were nematics.

Acknowledgement. The authors would like to express their sincere thanks to the Korea Science and Engineering Foundation for their support of this research. They are grateful to Dr. Robert Ausubel for his many helpful suggestion in the preparation of the manuscript.

\section{REFERENCES}

1. J.-I. Jin, S. Antoun, C. Ober, and R. W. Lenz, Br. Polym. J., 1980, 132 (1980).

2. R. W. Lenz and J.-I. Jin, Macromolecules, 14, 1405 (1981).

3. C. K. Ober, J.-I. Jin, and R. W. Lenz, Polym. J., 14, 9 (1982).

4. A. C. Griffin and S. J. Havens, J. Polym. Sci., Polym. Phys. Ed., 19, 951 (1981).

5. A. Roviello and A. Sirigu, Makromol. Chem., 183, 895 (1982).

6. A. C. Griffin and T. R. Britt, J. Am. Chem. Soc., 103, 4957 (1981).

7. J.-I. Jin, H.-T. Oh, and J.-H. Park, J. Chem. Soc., Perkin Trans. 2., in press.; H.-T. Oh, Master Thesis, Korea University, February, 1985.

8. A. Abe, Macromolecules, 17, 2280 (1984).

9. D.-Y. Yoon and S. Bruckner, "Configurational Characteristics of Thermotropic Polymers Comprising Rigid Groups Connected by Polymethylene Spacers,' IBM Research Report, RJ 4330 (47278), June 18, 1984, San Jose, Calif., U.S.A.

10. a) A. Blumstein, O. Thomas, J. Asrar, P. Makris, S. B. Clough, and R. B. Blumstein, J. Polym. Sci., Polym. Lett. Ed., 22, 13 (1984). b) E. T. Samulski and 
R. Dong, J. Chem. Phys., 77, 5090 (1982).

11. R. B. Blumstein, E. M. Stickles, and A. Blumstein, Mol. Cryst. Liq. Cryst., Lett., 82, 205 (1982).

12. J. A. Buglione, A. Roviello, and A. Sirigu, Mol. Cryst. Liq. Cryst., 106, 169 (1984).

13. J.-I. Jin, Y.-S. Chung, C. Ober, and R. W. Lenz, Bull. Korean Chem. Soc., 4, 143 (1983).
14. J.-I. Jin and J.-H. Park, Mol. Cryst. Liq. Cryst., 110, 293 (1984).

15. A. Abe, K. Tasaki, and J. E. Mark, Polym. J., 17, 895 (1985).

16. J.-I. Jin, E-Joon Choi, and Ki-Young Lee, Presented at the Annual Meeting of the Polymer Society of Korea, Kun-Kook University, Seoul, April 26, 1985. 